\title{
A capacidade jurídica pela Convenção sobre os Direitos da Pessoa com Deficiência e a insuficiência dos critérios do status, do resultado da conduta e da funcionalidade
}

\author{
The legal capacity of the Convention on the Rights of the person with disabilities and \\ the inadequacy of the Status criteria, the result of the conduct and the functionality
}

Joyceane Bezerra de Menezes*

\section{Resumo}

A Convenção sobre os Direitos da Pessoa com Deficiência impulsionou uma reviravolta no regime das incapacidades e no sistema de direito protetivo pautado na substituição de vontades. A partir dessa norma, a pessoa com deficiência possui igual capacidade legal em relação às demais, de modo que a deficiência não poderá ser utilizada como um critério modulador da capacidade jurídica, seja de modo direto, seja indireto. Para garantir a inclusão participativa da pessoa com deficiência, abandonaram-se os critérios que, ao longo da história, foram utilizados para modular a capacidade jurídica a partir da deficiência. Considerando que a limitação psíquica e/ou intelectual não é suficiente para negar a autonomia, tampouco a capacidade - ambos considerados corolários da dignidade -, a inclusão proposta pela Convenção implica a reabilitação da sociedade para acolher a pessoa com deficiência, em uma tentativa de otimizar a sua funcionalidade pela redução das barreiras.

Palavras-chave: Convenção sobre os Direitos da Pessoa com Deficiência. Capacidade civil. Autonomia.

\section{Abstract}

The Convention on the Rights of the disabled person has spurred a turnaround in the disabilities regime and the system of protective Law on the substitution of wills. From that standard, the disabled person has equal legal capacity in relation to others, so that disability cannot be used as a modulatory criterion of legal capacity, either directly or indirectly. To ensure the participatory inclusion of the disabled person, the criteria that throughout history have been used to modulate the legal capacity from the disability. Whereas the psychological and/or intellectual limitation is not sufficient to deny autonomy, nor the capacity - both considered corollaries of dignity -, the inclusion proposed by the Convention implies the rehabilitation of the society to accommodate the person with Disability in an attempt to optimize its functionality by reducing barriers.

Keywords: Convention on the Rights of the person with disabilities. Civil Ability. Autonomy.

\section{Introdução}

Muitos civilistas já denunciaram a insuficiência do regime das incapacidades tal qual previsto nos Códigos, haja vista a sua inadequação para o trato de questões existenciais. Argumentam que a titularidade dos direitos personalíssimos não pode se separar ou cindir-se ${ }^{1}$ da capacidade de exercício, inclusive em virtude de sua intransmissibilidade e inerência à determinada pessoa. ${ }^{2}$ Como esperar que alguém exerça

Doutora em Direito pela Universidade Federal de Pernambuco. Mestra em Direito pela Universidade Federal do Ceará. Professora titular da Universidade de Fortaleza. Programa de Pós-Graduação Strictu Senso em Direito (Mestrado/Doutorado) da Universidade de Fortaleza, na disciplina de Direitos de Personalidade. Professora adjunta da Universidade Federal do Ceará. Coordenadora do grupo de pesquisa CNPQ: Direito Constitucional nas Relações Privadas. Fortaleza-CE-Brasil. E-mail: joyceane@unifor.br.

Machado (2009, p. 25 e segs).

Na locução de Antônio Menezes Cordeiro (2011, p.108-109), há uma inerência dos direitos de personalidade à pessoa do titular e ao objeto tutelado. Assim, "nos direitos de personalidade uma primeira vertente de inerência é constituída pela intransmissibilidade da sua posição ativa. O direito de personalidade nasce na esfera de um titular e ficará aí até a sua extinção [...]. O direito de personalidade está, ainda, indissociavelmente ligado ao seu objeto. Ele reporta-se a um bem de personalidade, atingindo-o onde quer que ele se encontre. Na hipótese de uma circulação indevida de escritos ou de imagens que se devam considerar tutelados pelo regime da personalidade, o titular poderá agir onde quer que eles se encontrem." 
por outrem a liberdade de crença ou a liberdade de pensamento? Admitir-se tal possibilidade seria mesmo esvaziar o próprio direito. É por essa razão que, entre os próprios civilistas, sustentou-se a assertiva de que os direitos de personalidade somente podem ser exercidos pelo próprio titular. ${ }^{3}$

Para além da discussão sobre as características dos direitos personalíssimos, a filosofia dos direitos humanos propõe o realinhamento de conceitos como dignidade, autonomia e capacidade para favorecer a tutela das pessoas. Para mitigar ou eliminar as dificuldades que as pessoas com deficiência encontram para desfrutar os seus direitos, foi necessária a implementação de uma política global de não discriminação (ROIG, 2007).

A primeira fase da teoria dos direitos humanos, porém, fundamentava-se na ideia de dignidade humana associada a um protótipo de homem ideal, caracterizado por um padrão estético e ético específico, a que chamávamos de normalidade. Dotado da capacidade de raciocinar, de sentir e de se comunicar, tinha a participação franqueada no discurso moral (ROIG, 2012, p. 44-45). Esse homem abstrato e ideal, exemplo de normalidade, era o sujeito que gozava da "verdadeira" capacidade moral e da genuína liberdade de eleição, que não era reconhecida às pessoas com deficiência intelectual/psíquica. Ao pé da letra, essas últimas sequer poderiam se dizer titulares de "dignidade" - haja vista a carência daquelas capacidades acima mencionadas.

Na contemporaneidade, o sujeito moral dotado de dignidade é todo ser humano a quem se reconhece a liberdade de eleição e, consequentemente, a possibilidade de realizar seu plano de vida (PECES-BARBA, 2003). Observe-se, contudo, que essa liberdade de eleição, a partir de sua dimensão formal, não se restringe à aptidão para realizar escolhas concretas. Apresenta-se como um atributo inerente a todo ser humano igualitariamente (PECES-BARBA, 2003) e constitui a sua própria integridade moral, sem a qual ele se verá transformado em mero objeto (nem que seja de proteção). Sob essas razões é que se reconhece a liberdade de eleição e a autonomia (o uso dessa liberdade) à pessoa com deficiência, creditando-lhe, de igual modo, a capacidade jurídica (de exercício, sobretudo), que é a porta de acesso ao exercício dos direitos e obrigações, em igualdade com todas as demais pessoas.

Seguindo esse paradigma inclusivo, a Convenção sobre os Direitos da Pessoa com Deficiência (CDPD) estabeleceu o art. 12 que, por sua vez, é o fundamento primordial das mudanças havidas com a Lei Brasileira de Inclusão ou Estatuto da Pessoa com Deficiência (EPD), Lei n.13.146/2015. ${ }^{4}$ Pôs abaixo todos os critérios que direta ou indiretamente foram usados, ao longo da história, para modular a capacidade jurídica a partir da deficiência. Dentre esses critérios, listam-se: a abordagem do status (status approach), a abordagem do resultado (outcome approach) e a abordagem funcional (functional approach).

No atual estado da arte, entende-se que: sem a capacidade jurídica plena, a pessoa perde a chance de desenvolver e exercer as suas potencialidades e, com ela, o acesso aos direitos humanos, sobretudo a liberdade de eleição e o direito de realizar seu próprio plano de vida. Perde, igualmente, o direito de administrar sua fortuna e os seus bens, sua herança, o direito ao crédito, que também está garantido pela CDPD, à medida que a capacidade jurídica ali assinalada não se limita aos negócios existenciais e também se aplica à seara patrimonial (art. 12, item 5).

Na medida em que o exercício dessa capacidade jurídica conglobante (ARAUJO; RUZYK, 2017) se tornar uma tarefa difícil, a pessoa poderá ser beneficiada pelo chamado sistema de apoio. ${ }^{5}$ Por meio deste, a autonomia se desenvolve no contexto da interdependência e o apoiador acompanha a pessoa muito antes da formação do negócio jurídico, mas na concepção, amadurecimento e exteriorização de sua vontade.

Conforme Díez-Picazo (2003, p. 346), “como es lógico, la titularidad del derecho corresponde a la persona y, en princípio, solo seguramente, a ella. Es además, en línea de principio, un derecho de caráter personalísimo que solo el titular puede ejercer."

4 A CDPD é o primeiro tratado do sistema universal de direitos humanos do século XXI e, por meio dos princípios "in dubio pro capacitas" e "intervenção mínima", promove uma reviravolta no regime das incapacidades e no sistema de direito protetivo pautado na substituição de vontades. No Brasil, sua aprovação se deu por meio do Decreto n. 186/2008, com quórum qualificado de três quintos, nas duas casas do Congresso Nacional, em dois turnos, conforme instrui o art. $5^{\circ}, \S 3^{\circ}$, da Constituição Federal, o que Ihe conferiu a hierarquia de norma constitucional. Para evitar eventuais conflitos interpretativos quanto ao rito para ratificação dos tratados e, consequentemente, prejuízos à pessoa com deficiência, o Presidente da República ratificou e promulgou a Convenção por meio do Decreto Presidencial n . 6.949/2009.

5 No Brasil, temos a tomada de decisão apoiada, instituída pela Lei Brasileira de Inclusão ou Estatuto da Pessoa com Deficiência, que acrescentou o art.1.783-A ao Código Civil e a nova curatela, cuja disciplina também se acha nesta lei e no novo CPC. 
Pretende-se, com este texto, identificar o fundamento e os contornos da capacidade jurídica na CDPD, bem como os seus efeitos no regime jurídico das incapacidades brasileiro, analisando como se estabelece o apoio de modo breve e comparado aos instrumentos pautados na substituição da vontade.

Seguindo a metodologia do direito civil constitucional parte da premissa de que o ordenamento jurídico é unitário, o que implica a aplicação das normas infraconstitucionais em absoluta adequação às normas constitucionais, o que inclui, no âmbito da matéria em exame, a CDPD. A pessoa com deficiência psíquica e intelectual é, para os efeitos desta análise, o sujeito de carne a que se refere Rodotà (2011), qualificado por uma identidade única e sujeito a circunstâncias específicas de vida. O reconhecimento de sua capacidade jurídica é uma forma de inclusão na arena da vida jurídica, social e política, ao tempo em que possibilita a realização e a garantia de direitos humanos, fundamentais e civis, sem os quais estariam prejudicados a sua dignidade e o desenvolvimento de sua personalidade.

O texto se subdivide em três tópicos. No primeiro, aponta-se a insuficiência da capacidade jurídica prevista no direito civil tradicional enquanto uma estrutura binária que se subdivide em capacidade de gozo e capacidade de exercício, especialmente em face dos "direitos humanos". O segundo tópico trata do realinhamento dos conceitos de dignidade, autonomia e capacidade proposto pela filosofia dos direitos humanos albergados pela CDPD. O terceiro faz uma análise perfunctória sobre o modelo de apoio e sobre a possibilidade de sua coexistência com o sistema de substituição de vontade.

\section{Capacidade legal ou capacidade jurídica como expressão da dignidade}

Por meio da CDPD, as pessoas com deficiência, inclusive aquelas que possuem limitações intelectuais e/ou psíquicas, passaram a gozar de igual capacidade legal e do respeito à sua personalidade (art.12). A partir dessa premissa, o Estatuto da Pessoa com Deficiência ou Lei Brasileira de Inclusão (Lei n. 13.146/2015) reafirmou, de modo expresso, a revogação do regime das incapacidades, retirando qualquer referência à deficiência dos arts. $3^{\circ}$. e $4^{\circ}$. do Código Civil. De plano, rompeu com aqueles critérios que utilizam a deficiência para modular a capacidade.

Com isso, assistiu-se à inclusão paradigmática (ainda que no aspecto formal) de todas as pessoas que antes estavam privadas de uma maior e efetiva participação social, jurídica e política, porque não podiam exercer, por si, a titularidade de muitas situações subjetivas. ${ }^{6}$ Viviam sob a direção do representante legal, que manifestava a sua própria vontade para onerá-las nas esferas patrimonial e existencial.

Essa mudança suscitou uma série de questionamentos, os quais revelam: uma descrença na eficiência do sistema de apoio; a ideia de que as pessoas com deficiência psíquica e intelectual podem ser categorizadas como um só bloco homogêneo; e de que o exercício da autonomia somente pode se fazer pelo autogoverno, expressando decisões absolutamente autônomas e isentas de qualquer tipo de interferência alheia.

Partindo dessas premissas, muitos compreenderam que a capacidade legal mencionada pela CDPD estaria circunscrita à capacidade de gozo. Essa inquietação já estava presente nas discussões realizadas

6 A CDPD teve o condão de eliminar a aplicação da capacidade jurídica como barreira impeditiva do acesso aos direitos fundamentais. Sem a capacidade jurídica, muitos dos direitos fundamentais se esvaziam, notadamente aqueles cuja titularidade não se separa da capacidade de exercício, a exemplo da crença, da liberdade de expressão, do direito ao corpo, etc. Como explica Ferrajoli (2001, p. 22), "Personalidad, ciudadanía y capacidad e obrar, en cuanto condiciones de la igual titularidad de todos los (diversos tipos) de derechos fundamentales, son consecuentemente los parámetros tanto de la igualdad con de la desigualdad en droits fondamentaux. Prueba de ello es el hecho de que sus presupuestos pueden - y ha sido históricamente - más o menos extensos: restringidísimos en el pasado, cuando por sexo, nacimiento, censo, instrucción o nacionalidad se excluía de ellos a la mayor parte de las personas físicas, se han ido ampliando progresivamente aunque sin llegar a alcanzar todavía, ni siquiera en la actualidad, al menos por lo que se refiere a la ciudadanía y a la capacidad de obrar, una extensión universal que comprenda a todos los seres humanos. La ciudanía y la capacidad de obrar han quedado hoy como las únicas diferencias de status que aún delimitan la igualdad de las personas humanas. Tradução livre: "Personalidade, cidadania e capacidade de agir, enquanto condições comuns à igual titularidade de todos os (diversos tipos) direitos fundamentais, são consequentemente os parâmetros tanto da igualdade como da desigualdade nos direitos fundamentais. Prova disso é o fato de que seus pressupostos podem - e têm sido historicamente - mais ou menos extensos: restringidíssimos no passado, quando por sexo, nascimento, censo, educação ou nacionalidade se excluía a maioria das pessoas físicas, têm se expandido progressivamente, embora sem alcançar, nem mesmo no presente, pelo menos no que se refere à cidadania e à capacidade de agir, uma extensão universal que inclua todos os seres humanos. A cidadania e a capacidade de agir permanecem hoje como as únicas diferenças de status que ainda delimitam a igualdade das pessoas humanas". 
pelas delegações que compuseram o texto da Convenção, pois, durantes as sessões que discutiam a sua aprovação, houve uma proposta (vencida) de incluir, em nota de rodapé, a observação de que aquela capacidade significava a mera capacidade de gozo.

Mas a intenção da CDPD era muito maior. Visava instituir uma política global de inclusão e igualdade. Nessa esteira, a capacidade legal mencionada no art. 12 tratava-se mesmo da chamada capacidade jurídica plena que reúne o "gozo" e o "exercício". ${ }^{7}$ A Convenção optou por adotar a compreensão de que a capacidade jurídica e os princípios da dignidade da pessoa humana e da autonomia estão umbilicalmente correlacionados. ${ }^{8}$ Como explica Roig (2018), ${ }^{9}$ "o que se entende por capacidade no âmbito ético e jurídico são consequências da própria ideia de dignidade humana, tal e como tem sido construída desde sua origem (na modernidade) até nossos dias e que se apresenta como argumento justificador dos direitos".

Ao tempo em que é assegurada à pessoa o respeito à sua personalidade, dignidade, também se lhe reconhece a autonomia e capacidade jurídica em igualdade com as demais. Ainda que prevendo um sistema de apoio que ampara o sujeito no exercício dessa capacidade, conforme se verá adiante.

Essa compreensão confronta a orientação tradicional da teoria dos direitos humanos assentada sobre o protótipo do homem ideal, caracterizado como o indivíduo capaz de raciocinar, de sentir e de se comunicar; consequentemente, apto a participar do discurso moral por si só e a construir as normas da moralidade social. Naquela perspectiva, excluía-se do discurso aquele que não dispunha da "racionalidade exigida", a exemplo das crianças, ${ }^{10}$ das mulheres e das pessoas com deficiência intelectual e psíquica. Tais pessoas não podiam sequer decidir sobre o seu destino existencial, comportando-se como meros objetos da decisão dos sujeitos capazes (ROIG, 2012, p. 44). ${ }^{11}$

Alguns civilistas ${ }^{12}$ já mostraram a preocupação com essa forma de condicionar a participação das pessoas na rede de relações jurídicas experimentadas em sociedade. Perlingieri (2007) questionou o sistema das incapacidades pautado em critérios genéricos e abstratos. É imprescindível observar que a incapacidade ou capacidade para decidir podem, antes de tudo, ser fruto de uma circunstância temporal ou social (ROIG, 2012, p. 48), e não necessariamente de características pessoais estáticas. A criança ${ }^{13}$ que, em uma determinada fase da vida, é carente de autodeterminação, alcançará uma gradual autonomia ao longo de sua vivência, consolidando sua plena autonomia na vida adulta. Nesse caso, a capacidade natural de agir é gradual e relativa. Se considerarmos as circunstâncias sociais, uma eventual limitação física ou psíquica poderá ser agravada pelas barreiras do meio e, com isso, se converter em deficiência (até mesmo

“El concepto de 'capacidad jurídica' es un concepto más amplio, que, lógicamente presupone la capacidad de ser sujeto de derechos y obligaciones (elemento estático), pero también presupone la capacidad de ejercer dichos derechos, o asumir obligaciones a través de sus propias decisiones (elemento dinámico). Por ello, la ca- pacidad jurídica incluye la 'capacidad de obrar', entendida como la capacidad y la fa- cultad de una persona en virtud del derecho de asumir compromisos o transacciones particulares, mantener un estatus determinado, o una relación con otro, o, en un sentido más general, de crear, modificar o extinguir relaciones jurídicas" (BARIFFI, 2014, p. 303).

8 Sobre a reengenharia na capacidade jurídica, ver Menezes e Teixeira (2016).

9 "Los referentes que determinan lo que se entiende por capacidad en el ámbito ético y en el jurídico son consecuencia de la propia idea de dignidad humana, tal y como ha sido construida desde su origen (en la modernidad) hasta nuestros días y que se presenta como argumento justificatorio de los derechos" (ROIG, 2018). Ver também Palacios e Bariffi (2012, p. 1-2).

10 Sobre o reconhecimento da vontade jurígena da criança e do adolescente, importa a leitura dos seguintes autores: Stanzione e Sciancalepore (2006); Teixeira e Penalva (2008, p. 293-304); Tepedino (2010); Meireles (2008, p. 335-354); Menezes e Bodin de Moraes (2015, p. 501-532).

11 "En todo caso, y en lo que aquí interesa, estas personas que no superan ese estándar de racionalidad, como señalava antes no son sujetos sino objeto, quedando asi su horizonte moral pendiente de la decision de los capaces. Y esto ha provocado que el tratamiento de estas personas sea una cuestión de solidaridad y no necesariamente una cuestión de derechos. Sólo recientemente es possible hablar de un cambio que se percibe claramente en campo del tratamiento del menor y comienza a percibirse, de forma mucho más tímida, en la personas con discapacidad, consistente en adopter un enfoque de derechos. Ciertamente a ello han contribuído una enorme literature sobre ambas cuestiones y la aprobación de la Convención de Derechos del Niños y de la Convención de los derechos de las personas con discapacidad. Sin embargo, como señalaba antes, el cambio en relación con las personas con discapacidad es todavía muy timido y se enfrenta tanto a la manera en la que sociedad percibe estas situaciones cuando a la manera en la que el Derecho las aborda" (ROIG, 2012, p. 1-2).

12 Perligieri (2002, p. 163); Lôbo (2010, p. 121); Tepedino e Donato (2016, p. 237) destacaram a inviabilidade de se apartar a titularidade e a capacidade de exercício relativa aos direitos existenciais.

13 Sobre a posição da criança, também se tem uma ampliação do respeito à sua autonomia. Com Roig (2012, p. 45), "aunque no se podría afirmar que la CDN reconoce el derecho pleno al ejercicio de la capacidad jurídica del niño, lo cierto es que incorpora algunas disposiciones y principios que tienen como objetivo justamente cuestionar los modelos paternalistas y tutelares donde los niño sólo pueden ejercer sus derechos y tomar decisiones jurídicamente vinculantes por intermedio de sus padres o representantes legales". Tradução livre: "Ainda que não se possa afirmar que a CDN reconhece o pleno exercício da capacidade juridica à criança, o certo é que incorpora algumas disposições e princípios que têm como objetivo justamente questionar os modelos paternalistas e tutelares em que as crianças só podem exercer seus direitos e tomar decisões juridicamente vinculantes por intermédio de seus pais ou representantes legais". 
severa), com gravíssimo impedimento pessoal. Exemplifica-se o impedimento legal ao casamento que vigia anteriormente ao Estatuto como barreira à construção de plano afetivo familiar. Fora os impedimentos jurídicos, não custa lembrar que, sem o apoio e o investimento familiar e social, ninguém, tampouco o sujeito que sofre uma limitação intelectual, logrará efetivo êxito em seu projeto emancipatório. Todos precisamos de apoio. E a pessoa com limitações funcionais, na área física, intelectual e/ou psíquica, pode precisar de um suporte ainda maior.

Um maior talento pessoal para raciocinar, sentir e se comunicar não representará uma maior dignidade. Rompe-se, na contemporaneidade, a ideia de que a dignidade da pessoa humana está associada àquele protótipo de ser humano ideal, pautado no ideal abstrato de perfeição estético e ético (PECES-BARBA, 2003). Até porque, repita-se, o maior talento, na maioria das vezes, é o resultado de um maior investimento em estímulos e oportunidades que, historicamente, foram negadas à pessoa com deficiência, até recentemente desconsiderada em sua autonomia moral (ROIG, 2012, p. 53).

Nos dias atuais, ao lado do princípio da dignidade da pessoa humana, opera o princípio da igualdade e da não discriminação, por meio do qual se considera discriminatório o tratamento diferente que se baseia em critérios não relevantes e o tratamento igualitário que desconsidera circunstâncias relevantes (ROIG, 2012, p. 51) ${ }^{14}$ A limitação psíquica e/ou intelectual não são suficientes para negar a autonomia, tampouco a capacidade, pois ambas são consideradas corolários da dignidade..$^{15}$

Tal limitação não é uma doença ou uma anomalia, consubstancia um fator de diversidade (PALACIUS; ROMANACH, s./d.) que não pode ser usado como critério discriminatório para negar direito ou o acesso à participação social pela mitigação da capacidade jurídica.

Enquanto a enfermidade está relacionada a uma alteração mais ou menos grave da saúde; a deficiência pode se expressar em termos de diversidade funcional, associada ou não a uma enfermidade ou não. Alguém que contrai uma pneumonia, por exemplo, pode sofrer redução nas funções respiratórias e, inclusive, laborais. Aquele que desenvolve Alzheimer sofrerá disfunção cognitiva grave. As vítimas de poliomielite podem sofrer impacto nas pernas ou braços e, consequentemente, limitações em sua mobilidade. Mas nem toda diversidade funcional deriva de uma doença. Pessoas que sofreram uma paralisia cerebral no momento do parto e foram diagnosticadas com um transtorno psíquico, ou com uma síndrome que implica deficiência intelectual, podem apresentar uma diferença na sua expressão funcional sem que isto esteja correlacionado a uma enfermidade.

Ademais, a despeito de um mesmo diagnóstico, as pessoas respondem aos desafios da vida de modo diferenciado, apresentando capacidades funcionais distintas, com uma maior ou menor independência. Disso resulta que a limitação funcional não deve ser apreciada de modo isolado, com foco apenas na pessoa e sem uma referência ao meio externo, ${ }^{16}$ pois o background do meio pode ampliar aquela funcionalidade ou

\footnotetext{
4 Transcrição no original: "Se considera así como discriminatorio tanto el trato diferente basado en circunstancias no relevantes, cuanto el trato no diferente desconocedor de circunstancias relevantes. Las circunstancias que se tienen en cuenta en este campo se corresponden bien con rasgos de las personas (lo que puede ser entendido como enfoque de la identidad) bien con situaciones en las que se encuentran las personas (lo que puede ser entendido como enfoque de la situación)" (ROIG, 2012, p. 51).

15 Transcrevendo o trecho do Comitê sobre os Direitos da Pessoa com Deficiência da ONU sobre o art.12, Item 8. "El artículo 12 de la Convención afirma que todas las personas con discapacidad tienen plena capacidad jurídica. La capacidad jurídica les ha sido negada de forma discriminatoria a muchos grupos a lo largo de la historia, como las mujeres (sobre todo al contraer matrimonio) y las minorías étnicas. Sin embargo, las personas con discapacidad siguen siendo el grupo al que más comúnmente se le niega la capacidad jurídica en los ordenamientos jurídicos de todo el mundo. El derecho al igual reconocimiento como persona ante la ley entraña que la capacidad jurídica es un atributo universal inherente a todas las personas en razón de su condición humana y debe defenderse para las personas con discapacidad en igualdad de condiciones con las demás. La capacidad jurídica es indispensable para el ejercicio de los derechos económicos, sociales y culturales. Adquiere una importancia especial para las personas con discapacidad cuando tienen que tomar decisiones fundamentales en lo que respecta a la salud, la educación y el trabajo. (En muchos casos, la negación de capacidad jurídica a las personas con discapacidad ha conducido a privarlas de muchos derechos fundamentales, como el derecho de voto, el derecho a casarse y fundar una familia, los derechos de reproducción, la patria potestad, el derecho a otorgar su consentimiento para las relaciones íntimas y el tratamiento médico y el derecho a la libertad.) (Comité sobre los Derechos de las Personas con Discapacidad. $11^{\circ}$ período de sesiones. 30 de marzo a 11 de abril de 2014. Tema 10 del programa provisional. Observaciones generales y días de debate general)" (Grifo intencional).

16 "Art. $1^{\circ}$. Pessoas com deficiência são aquelas que têm impedimentos de longo prazo de natureza física, mental, intelectual ou sensorial, os quais, em interação com diversas barreiras, podem obstruir sua participação plena e efetiva na sociedade em igualdades de condições com as demais pessoas."
} 
agravá-la. ${ }^{17} \mathrm{~A}$ pessoa que perdeu a perna e passou a usar prótese de titânio poderá alcançar um desempenho ainda superior ao que tinha antes. ${ }^{18} \mathrm{~A}$ criança com déficit cognitivo por limitação intelectual ou psíquica pode, com o devido apoio e os estímulos necessários, alcançar patamares consideráveis de autonomia para uma vida independente.

A inclusão proposta pela CDPD implica a reabilitação da sociedade para acolher a pessoa com deficiência na tentativa de otimizar a sua funcionalidade pela redução das barreiras, pelas adaptações razoáveis, pela tecnologia assistiva, etc. Essa inclusão impõe a utilização do meio como fator de integração funcional.

Esse ajuste amplia a responsividade do sujeito, como assinala Amundson (GAUDENZI; ORTEGA, 2016, p. 3067). A capacidade do sujeito em responder aos desafios externos é mensurada não apenas pela sua força e determinação intrínsecos, mas também pela modificação do meio externo. Na sugestão de Canguilhem (2012, p. 124), "cabe a nós acolhermos ou não o diferente, criando condições de estímulo às respostas normativas dos sujeitos individuais".

Seguindo essa orientação, o termo "diversidade funcional" propõe a ruptura com aquelas palavras carregadas de sentido discriminatório que ainda são utilizadas para identificar a pessoa como "deficiente", "incapaz", "limitado", "anormal", "inválido", "interditado". ${ }^{19}$ Esses termos remetem a pessoa a uma condição inferior às demais, ressaltando a insuficiência de suas características funcionais comparativamente às demais. ${ }^{20}$ Toda essa abordagem se fundamenta no superado modelo médico que identifica no sujeito, e somente nele, os efeitos da limitação física, psíquica ou intelectual, desconsiderando os agravantes originários do meio externo e/ou a inexistência de instrumentos de ampliação funcional neste mesmo meio.

Para fortalecer a inclusão, além da mitigação das barreiras e do background do meio externo, é necessário aplicar o conceito de autonomia na interdependência, oportunizando à pessoa o apoio de que necessitar. Nesse caso, a autonomia se faz na interdependência, e não exclusivamente por um "autogoverno" isolado, sem qualquer ajuda externa. Implica reconhecer à pessoa com deficiência a sua personalidade e a capacidade de decisão, para que possa participar igualitariamente nas relações jurídicas, ${ }^{21}$ exercendo, por si e/ou sob apoio, os direitos e cumprindo, também por si, os deveres correspondentes.

A virada copernicana está na superação da deficiência como critério aplicável à modulação da capacidade e na possibilidade da autonomia na interdependência (DANDHA, 2007, p. 439).

Infelizmente, a despeito da presunção de capacidade viger como um postulado imemorial, a pessoa com deficiência, sobretudo aquela decorrente de limitações na seara psíquica ou intelectual, sofre uma presunção juris tantum de "incapacidade". Esta foi a razão para a implementação de uma política global de não discriminação, tal como a delineada pela CDPD (ROIG, 2007).

17 "Em muitos casos, a suposta falha no desempenho pode ser reparada pela tecnologia aplicada pelos humanos. É o caso dos óculos, dos aparelhos de surdez, da comunicação de autistas facilitada por computador e das inúmeras próteses. A ação deliberada de adequação do meio para manutenção de uma vida satisfatória permite que o disfuncional em alguns casos se torne perfeitamente funcional." (GAUDENZI; ORTEGA, 2016, p. 3067).

18 Interessante a reportagem que destaca a evolução das próteses e o aumento do desempenho dos seus usuários. (TRINDADE, 2016). Disponível em: < http://www.otempo.com.br/hotsites/rio-2016/evolu\%C3\%A7\%C3\%A3o-nas-pr\%C3\%B3teses-leva-\%C3\%A0-melhora-nas-performances-1.1290035>. Acesso em: 16 abr. 2018.

19 "Por eso el término 'diversidad funcional' se ajusta a una realidad en la que una persona funciona de manera diferente o diversa de la mayoría de la sociedad. Este término considera la diferencia de la persona y la falta de respeto de las mayorías, que en sus procesos constructivos sociales y de entorno, no tienen en cuenta esa diversidad funcional." (PALACIOS; ROMAÑACH, s./d., p. 107).

20 "Las mujeres y hombres con diversidad funcional tie-nen que ver con sociedades que, siendo intrínse-camente imperfectas, han establecido un modelo de perfección al que ningún miembro concreto de ellas tiene acceso, y que definen la manera de ser física, sensorial o psicológicamente, y las reglas de funciona- miento social. Y que este modelo está relacionado con las ideas de perfección y 'normalidad' establecidas por un amplio sector que tiene poder y por el concepto de mayorías meramente cuantitativas." (PALACIOS; ROMAÑACH, s./d., p. 106).

21 Para Amita Dandha (2007, p. 435-436), "human rights scholars argue convincingly that article 12 of the CRPD vests persons w. ith disabilities with both of these aspects of legal capacity. 6 In other words, the capacity to hold rights automatically entails the capacity to exercise them with appropriate supports acceptable to and chosen by each individual". Tradução livre: "Os estudiosos dos direitos humanos argumentam de forma convincente que o artigo 12 da Conveção CRPD pessoas com deficiência com ambos os aspectos da capacidade legal. Em outras palavras, a capacidade de possuir direitos implica automaticamente a capacidade de exercê-los com os apoios apropriados aceitáveis e escolhidos por cada indivíduo." 
Essa política global, porém, implica uma mudança paradigmática que afeta algumas instituições anacrônicas e defasadas, ${ }^{22}$ fundamentadas muito mais numa tradição legal de tempos pretéritos do que nos critérios e nas concepções de justiça e igualdade que balizam os direitos humanos na contemporaneidade (BARIFFE, 2014, p. 264). Priorizam-se os Códigos ou os direitos humanos? Direitos humanos são normas metajurídicas? Certamente que a CDPD tem outra natureza: é norma constitucional de eficácia direta e aplicabilidade imediata.

A partir dessa norma, a pessoa com deficiência possui igual capacidade jurídica (ou capacidade legal, como diz o texto original) em relação às demais, de sorte que a deficiência não poderá utilizada como um critério modulador da capacidade jurídica, seja de um modo direto, seja de modo indireto. Por outro lado, impõe-se a que a pessoa com deficiência psíquica e intelectual seja estimulada no exercício de sua autonomia a partir da infância, conforme se dispõe quanto aos projetos educacionais. Não apenas o cuidado, mas o cuidado e a emancipação na interdependência são o norte das relações humanas. Todos necessitam de maior ou menor cuidado ao longo da vida. ${ }^{23}$

\section{A insuficiência dos critérios que usaram a deficiência para modular a capacidade jurídica}

Em face de tudo o que se disse, nenhum dos critérios utilizados historicamente para abordar a deficiência no regime das incapacidades - quais sejam, a abordagem do status (status approach), a abordagem do resultado da escolha (outcome approach) e a abordagem funcional (functional approach) -, poderá ser aplicado sem ofensa frontal à Convenção. ${ }^{24}$ Pelo primeiro critério, o próprio estado da deficiência seria o critério incapacitante. A simples ocorrência de uma deficiência específica (notadamente aquela de ordem psíquica e intelectual) seria suficiente para privar a pessoa da capacidade jurídica, independentemente das suas capacidades concretas e reais.

Pelo segundo critério, enfocam-se os resultados das escolhas realizadas pela pessoa para aferir a sua capacidade. Nessa medida, aquele que faz escolhas desassisadas e irrazoáveis, segundo o juízo social de uma determinada época, poderá sofrer uma modulação na sua capacidade. Recentemente, um jovem goiano de 25 anos recusou o tratamento de hemodiálise, essencial à sua saúde, e foi, por essa razão, submetido à curatela, mesmo quando o laudo pericial não concluiu por um déficit cognitivo na realização daquela escolha. ${ }^{25} \mathrm{O}$ último critério observa a funcionalidade do sujeito, ou seja, a sua capacidade natural de, por si próprio, compreender, discernir, decidir, raciocinar, avaliando a conveniência e os efeitos das suas decisões. Ao seguir esse critério, o sujeito será considerado capaz se demonstrar a capacidade de realizar escolhas informadas por si só, sem qualquer auxílio dos demais.

A legislação brasileira já fez uso de todos esses critérios. O Código Civil de 1916 utilizou o status approach, arrolando entre os absolutamente incapazes "os loucos de todos os gêneros". ${ }^{26}$ Pelo outcome

22 "La persona no es exclusivamente para el Derecho civil el titular de derechos y obligaciones o el sujeto de relaciones jurídicas. Si esta rama del ordenamento jurídico se caracteriza basicamente por ser la dedicada a la persona en sí misma considerada, debe ocuparse de la protección de sus atributos físicos y morales, de su libre desarrrolo y desenvolvimiento." (DIEZ-PICASO, 2003, p. 327).

23 A filósofa feminista Eva Kittay preocupa-se em desmontar as teorias liberais da justiça e igualdade ao sustentar que as relações de dependência são inevitáveis na vida social e inescapáveis à história de vida de todas as pessoas. Cuidado e interdependência, diz, são princípios que estruturam a vida social e impõem a centralidade da dependência nas relações humanas. A autora americana fez uso da ideia de que "somos todos filhos de uma mãe" para dizer que todos somos cuidados por alguém em algum momento da vida. A partir da noção de self transparente, isto é, do self moral daquele que tem o dever de cuidar de outras pessoas e é movido por um ideal altruísta, baseado nos laços de afeto e preocupação, reitera que o sujeito moral é inerentemente relacional, contrapondo-se à interpretação de self da tradição liberal. Nesta concepção, o self transparente é o elemento moral central da ética do cuidado. Trata-se de uma forma de compreender o indivíduo e a moralidade diferente da definição tradicional do ser humano nas sociedades capitalistas ocidentais, em que o indivíduo é prioritariamente percebido como sujeito independente, submetido apenas a si mesmo e ao comando da razão. [...] Esvaziar as noções de capacidade individual e independência e fortalecer as ideias de interdependência e relação interpessoal como critérios de julgamento da condição variante permitem que o julgamento da deficiência seja relativizado" (GAUDENZI; ORTEGA, 2016, p. 3067).

24 CONCIL OF EUROPE (2012).

25 Notícia veiculada pelo Jornal "Estadão". Justiça determina interdição de jovem que recusa hemodiálise para morrer em Goiânia. Disponível em: <http://saude.estadao.com.br/noticias/geral,justica-determina-interdicao-de-jovem-que-recusa-hemodialise-para-morrer-em-goiania,70002099942 $>$. Acesso em: 14 abr. 2018.

$26 \mathrm{CC} / 1916$, Art. 5 São absolutamente incapazes de exercer pessoalmente os atos da vida civil: 
approach, o Código Civil de 1916 previu a modulação da capacidade do "pródigo", no que foi seguido pelo Código Civil de 2002. ${ }^{27}$ Coube ao Código Civil de 2002 adotar o functional approach, definindo como absolutamente incapaz para o exercício dos atos da vida civil a pessoa com "enfermidade ou deficiência mental" sem o necessário "discernimento" para a prática desses atos. ${ }^{28}$ Além disso, definindo como relativamente incapaz para a prática de determinados atos da vida civil a pessoa que, por causa da "deficiência mental", tinha o "discernimento" reduzido, e de igual modo a pessoa "excepcional" sem o "desenvolvimento completo". ${ }^{29}$

Quaisquer desses critérios expõem a pessoa com deficiência (psíquica e intelectual) a uma condição limiar na qual a sua capacidade é sempre questionada (DANDHA, 2007). Por essa razão, diz-se que a CDPD rompeu com todos eles. Utilizam a deficiência como critério direto ou indireto para reduzir ou negar a capacidade da pessoa, dispensando-Ihe um tratamento discriminatório. Na perspectiva de Dandha, dentre os critérios apresentados o functional approach poderá atender à CDPD se a sua aplicação estiver voltada à delimitação dos limites do apoio a ser direcionado à pessoa na facilitação do exercício de sua capacidade jurídica. Do contrário, se aplicável para modular ou suprimir a capacidade, não será adequado à política global de inclusão proposta pela CDPD (2007, p. 457). Nessa mesma direção posicionou-se o Comitê da ONU sobre os Direitos da Pessoa com Deficiência. ${ }^{30}$

Rotular a pessoa com a "incapacidade" pode trazer prejuízos irreparáveis ao seu desenvolvimento e constituir uma profecia "auto-realizável". ${ }^{31}$ Lançado à condição de incapaz, o sujeito não será estimulado a aprender e a desenvolver determinadas tarefas. Privado do continuado exercício de decidir, ver-se-á confinado à perene passividade. Para evitar esse destino a CDPD propôs uma ampla inclusão, pautada na mudança atitudinal da família, da escola e da sociedade, no sentido de acreditar e estimular a pessoa a uma vida independente - ou melhor, interdependente.

Além da rede de apoios sociais, a CDPD impõe aos Estados signatários a instituição de mecanismos de apoio ao exercício da capacidade jurídica. Tais instrumentos rompem com o sistema de substituição de vontade que complementava o regime das incapacidades na tutela da pessoa com deficiência. No Brasil, a curatela se estabelecia, na maioria das vezes, com os poderes de representação legal, cabendo ao curador o dever de substituir o curatelado nos atos da vida civil.

27 CC/1916, Art. 6 São incapazes, relativamente a certos atos (art. 147, n. 1), ou à maneira de os exercer: [...] II. Os pródigos. CC/2002, Art. 4으ão incapazes, relativamente a certos atos ou à maneira de os exercer: [...] IV - os pródigos.

$28 \mathrm{CC} / 2002$, Art. 3० São absolutamente incapazes de exercer pessoalmente os atos da vida civil: [...]

II - os que, por enfermidade ou deficiência mental, não tiverem o necessário discernimento para a prática desses atos;

29 CC/2002, Art. 4-São incapazes, relativamente a certos atos ou à maneira de os exercer: [...] II - os ébrios habituais, os viciados em tóxicos, e os que, por deficiência mental, tenham o discernimento reduzido; III - os excepcionais, sem desenvolvimento mental completo;".

30 O próprio Comitê da ONU também já se posicionou contrariamente a esses critérios, senão leia-se: "En la Observación General No 1 el CteCDPD señala que: [...] En la mayoría de los informes de los Estados partes que el Comité ha examinado hasta la fecha se mezclan los conceptos de capacidad mental y capacidad jurídica, de modo que, cuando se considera que una persona tiene una aptitud deficiente para adoptar decisiones, a menudo a causa de una discapacidad cognitiva o psicosocial, se le retira en consecuencia su capacidad jurídica para adoptar una decisión concreta. Esto se decide simplemente en función del diagnóstico de una deficiencia (criterio basado en la condición), o cuando la persona adopta una decisión que tiene consecuencias que se consideran negativas (criterio basado en los resultados), o cuando se considera que la aptitud de la persona para adoptar decisiones es deficiente (criterio funcional). El criterio funcional supone evaluar la capacidad mental y denegar la capacidad jurídica si la evaluación lo justifica. A menudo se basa en si la persona puede o no entender la naturaleza y las consecuencias de una decisión y/o en si puede utilizar o sopesar la información pertinente. Este criterio es incorrecto por dos motivos principales: a) porque se aplica en forma discriminatoria a las personas con discapacidad; $y$ b) porque presupone que se pueda evaluar con exactitud el funcionamiento interno de la mente humana y, cuando la persona no supera la evaluación, le niega un derecho humano fundamental, el derecho al igual reconocimiento como persona ante la ley. En todos esos criterios, la discapacidad de la persona o su aptitud para adoptar decisiones se consideran motivos legítimos para negarle la capacidad jurídica y rebajar su condición como persona ante la ley. El artículo 12 no permite negar la capacidad jurídica de ese modo discriminatorio, sino que exige que se proporcione apoyo en su ejercicio...]" Observación general No 1 (2014), Artículo 12: Igual reconocimiento como persona ante la ley, CRPD/C/GC/1, 19 de mayo de 2014, párrafo 15.

31 Na tese de Dandha (2007, p. 439), "development of human capabilities enables human beings to undertake all the doings and functions required to live a complete human life. But such capability development can happen only if every human being is accorded the opportunity to so live life as to realize his or her own inner genius. In my understanding, it then follows that in order to enable an individual to develop such capabilities, it is important that such individual be presumed to have the capacity to do so. In a major piece detailing the side effects of the label of incompetence, Bruce Winck provides psychological insights on how individual personality development is affected by such labels. A label of incompetence can often play out as a self-fulfilling prophecy. Once a finding is reached that a person is incompetent to perform certain tasks, such person shall not be given any opportunity to engage in or learn those tasks. It follows from Winck's analysis that if a person is denied the opportunity to fulfill certain life activities, he or she fails to develop the capabilities required to perform those activities". 


\section{O apoio como instrumento de integração funcional no exercício da capacidade e as possibilidades de sua coexistência com a substituição de vontade}

Sob a proposta da CDPD a deficiência não será critério modulador da capacidade. Porém, a depender da limitação psíquica e intelectual, a pessoa poderá necessitar de um apoio ao exercício de sua capacidade. Tal apoio importa no suporte adequado para que possa identificar e comunicar seus desejos. Implica um acordo de confiança e de respeito à vontade da pessoa apoiada (BARIFFI, 2014, p. 366).

Cada Estado signatário deverá instituir instrumentos de apoio jurídico à tomada de decisão com as salvaguardas necessárias a que os direitos da pessoa não sejam ameaçados. A delimitação do apoio se fará em conformidade com as necessidades da pessoa, podendo ser mais brando ou mais intenso, mas respeitando-se, em todo caso, os seus direitos e salvaguardas (CDPD, preâmbulo, alínea J).

Sob o prisma da CDPD, mesmo o apoio mais intenso não pode implicar substituição de vontade. $\mathrm{Na}$ orientação de Roig (2009, p. 55),

[...] o sistema de apoio deve: i. Ser capaz de respeitar ao máximo a autonomia da pessoa com diversidade mental ou intelectual; ii. Ser permeada aos distintos tipos de diversidade e circunstancias concretas de cada pessoa; iii. Ter a menor duração possível e ser revista periodicamente; iv. Sacrificar no menor grau possível os direitos da pessoa. ${ }^{32}$

No Brasil, o Estatuto da Pessoa com Deficiência instituiu a chamada tomada de decisão apoiada, acrescentando o art.1.783-A ao Código Civil, e reformulou a Curatela a partir do art.84. O primeiro instituto é notoriamente adequado à CDPD visto que reafirma a autonomia e que não mitiga ou reduz a capacidade do apoiado. ${ }^{33}$ Mas quanto à curatela, restam algumas dúvidas. Observa-se, no EPD, a tentativa de revestir o instituto tradicionalmente presente na legislação pátria, com a natureza de apoio.

Por meio do art. 84, caput, situado no Capítulo intitulado "Do igual reconhecimento perante a lei", reafirmou o direito da pessoa com deficiência em exercer a sua capacidade em igualdade de condições com as demais pessoas. No parágrafo primeiro do mesmo dispositivo, previu que "quando necessário, a pessoa com deficiência será submetida à curatela, conforme a lei."

As leis aplicáveis à curatela são o Código Civil e o Código de Processo Civil. ${ }^{34} \mathrm{O}$ Código Civil teve parte de suas normas alteradas pelo EPD, mas ainda dispôs, no art.1.767, que as pessoas sujeitas a essa medida seriam aquelas que, "por causa transitória ou permanente, não puderem exprimir sua vontade". Nos termos do art. $4^{\circ}$, III, do mesmo Código, tais pessoas são consideradas relativamente incapazes "a certos atos ou à maneira de os exercer". Disto se deduz que toda pessoa sujeita à curatela sofre uma modulação na sua capacidade civil, tornando-se relativamente incapaz.

Como a alternativa da curatela continua sendo aplicada às pessoas com deficiência com muita recorrência no país, inclusive àquelas que poderiam manifestar a vontade se estivessem sob um apoio mais consistente, teme-se que a CDPD esteja sendo pouco respeitada. ${ }^{35}$

32 No original: "Así, el sistema de apoyo debe: (i) ser capaz de respetar al máximo la autonomía de la persona con diversidad mental o intelectual; (ii) ser permeable a los distintos tipos de diversidad y a las circunstancias concretas de cada persona; (iii) tener la menor duración posible y ser revisables periódicamente; (iv) sacrificar en el menor grado posible los derechos de la persona" (ROIG, 2012, p. 55).

Sobre tomada de decisão apoiada, ver Menezes (2016)

Sobre a curatela, ver Menezes (2015).

Teme-se que, sob a justificativa de que a pessoa não pode manifestar a vontade por si, e desconsiderando a integração de sua funcionalidade pelo apoio, acabe-se desconsiderando a determinação da CDPD. Conforme Dandha (2007, p. 429), "Further, these reform efforts acknowledged that, if assistance is required to exercise capacity, then such assistance should be provided instead of holding a person to be incompetent. Accepting this premise, legal systems experimented with establishing legally recognized persons who could provide this assistance. A finding of incompetence in traditional legal systems has resulted in guardians of person or property being appointed, who then were charged with making decisions on behalf of the incompetent person. In comparison, it reform efforts were aimed at supporting rather than supplanting the person in need of assistance. The possibility of substitution, however, has been retained." Tradução livre: "Além disso, esses esforços da reforma reconheceram que, se for necessária assistência para o exercício da capacidade, tal assistência deve ser prestada em vez de impedir que uma pessoa seja considerada incompetente. Aceitando essa premissa, os sistemas legais admitem que as pessoas estabelecidas em lei possam exercer o múnus da assistência. A constatação de incompetência nos sistemas jurídicos tradicionais resultou na possibilidade de nomeação de curadores ou tutores da pessoa para questões existenciais ou patrimoniais, encarregando-as de tomar decisões em nome da pessoa considerada incompetente. Enquanto os esforços da reforma visavam apoiar, em vez de suplantar, a pessoa necessitada de assistência; a possibilidade de substituição, no entanto, foi mantida". 
Toda essa problemática requer maior reflexão, especialmente nos casos em que a pessoa vivencia uma situação concreta que impossibilita, mesmo com todo o apoio, uma manifestação volitiva. Numa situação excepcional como esta, o enfoque deverá ser o da situação de vida, e não a deficiência em si. ${ }^{36}$

A se considerar a leitura de Francisco Bariffi (2014, p. 391), o artigo 12, item 2, da CDPD, não implica um direito absoluto ao exercício da capacidade pela pessoa com deficiência, mas estabelece a garantia de que a deficiência não será usada como critério a restringir tal capacidade. Se vier a fazê-lo, será por meio de um critério aplicável a qualquer sujeito.

Nessas hipóteses, excepcionalíssimas, a pessoa poderá ser posta sob proteção específica. Porém, ainda que sob representação legal, não deverá se sujeitar ao talante do representante, conforme instrui o tradicional sistema da substituição de vontade. Suas preferências e a sua vontade, manifestas ao tempo em que podia se posicionar, seja pela forma como viveu, seja pelos afetos, seja mesmo por declarações verbais, devem ser respeitadas. Na hipótese em que sofrer limitações gravíssimas desde o nascimento, impeditivas de qualquer manifestação volitiva, seus interesses fundamentais deverão sempre ser respeitados pelo representante.

Não se pode autorizar uma ampla substituição de vontade para onerar o curatelado em todos os atos da vida civil. Anteriormente, o curador se imiscuía em assuntos existenciais e se via com poder para decidir sobre doação de órgãos ${ }^{37}$ e sobre esterilização sem qualquer parcimônia, por exemplo. Isto não se pode admitir. ${ }^{38} 39$

A matéria da substituição de vontade é tema muito polêmico até entre os estudiosos de direitos humanos. Embora o texto da CDPD não tenha revogado expressamente o sistema de substituição de vontade, foi enfático quanto à aplicação desse sistema de apoio e salvaguardas. Considerando que os países signatários não adotam esse sistema de apoio, insistindo nas soluções pautadas na substituição de vontade, a Organização das Nações Unidas (ONU), por meio do Comitê de Direitos da Pessoa com

36 Essa é a sugestão de Roig (2009, p. 7): "Por otro lado la Convención opta por el enfoque de la situación frente al enfoque de la identidad, lo que obliga a que cuando se abandone ese modelo de apoyo, por ejemplo en situaciones en las que no sea posible conocer la voluntad de la persona, se haga en razón de la situación determinada, y nunca en razón de la discapacidad".

37 "É ilustrativo dessa questão um julgamento proferido pelo Tribunal de Justiça de São Paulo, no ano de 1986. No âmbito da Apelação Cível 76.123-1, o Tribunal analisou a possibilidade de um interdito com "psicose epilética, na forma demencial", efetuar a doação de um rim a irmão dele, que apresentava insuficiência crônica terminal. A decisão monocrática acolheu o pedido formulado pelo curador do incapaz, de suprimento de consentimento, a partir do qual o transplante seria autorizado. Inconformado, o Ministério Público interpôs recurso de apelação. O Tribunal deu provimento à apelação e reformou a sentença, sob o argumento de que o interdito tinha "vida simplesmente vegetativa, sem condições de comunicar-se ou manifestar a vontade ainda que de forma defeituosa". E, em vista da natureza "personalíssima" da decisão de doar órgãos humanos, o curador não poderia anuir em nome do incapaz. Não aprofundaremos a análise do caso em comento propriamente, se a decisão do Tribunal foi ou não acertada. Interessam-nos os princípios que dele poderemos extrair. Suponhamos, para efeito de argumentação, que o interdito, apesar da doença mental, tivesse condições de manifestar de forma segura, isenta, a sua vontade. Mesmo assim, se reproduzirmos os fundamentos do acórdão (que, para o caso concreto, nos parecem pertinentes), o transplante não poderia ser realizado. A interdição civil, conforme implementada hoje em dia, ao mirar a proteção dos bens do incapaz, acaba suprimindo sua capacidade não apenas para os atos patrimoniais, mas também para as situações existenciais, para o exercício de direitos da personalidade. Com isso, o interdito não pratica os atos existenciais ele próprio, como efeito da perda da capacidade, nem através do curador, dado o caráter personalíssimo desses atos. Ou seja, nesses moldes, a interdição, que seria medida de proteção do incapaz, resulta na verdade em medida de exclusão (TJSP, Ap 76.123-1, 5a Câmara, j. 14-8-1986, rel. Ruy Camilo)." (LEITE, 2012, p. 302-321).

38 "SUPRIMENTO JUDICIAL - Curador provisório que pede a esterilização da interditada - Acolhimento - Possibilidade - Interpretação histórica e teleológica do decreto $n^{\circ} 6.949$, que promulga a convenção internacional sobre direitos das pessoas com deficiência e seu protocolo facultativo - Decisão reformada - Recurso provido. (TJ-SP - APL: 00009916620148260654 SP 0000991-66.2014.8.26.0654, Relator: Alvaro Passos, Data de Julgamento: 22/09/2015, $2^{a}$ Câmara de Direito Privado, Data de Publicação: 29/09/2015)"; em outra decisão, "Alvará Judicial. Cirurgia de Laqueadura. Pessoa interditada portadora de deficiência mental e motora e que já é mãe. Indicação feita pelo médico. Interesse processual e possibilidade jurídica do pedido demonstradas. Extinção afastada. Aplicação do art. $515, \S 3^{\circ}$, do CPC. Tendo em vista que a autora já passou pelo processo de interdição, por outro lado, despicienda a necessidade de realização de nova perícia médica pelo IMESC. Procedência do pedido. Sentença reformada. Recursos providos.”. (TJ-SP - APL: 00007742320148260654 SP 0000774-23.2014.8.26.0654, Relator: Pedro de Alcântara da Silva Leme Filho, Data de Julgamento: 12/08/2015, $8^{a}$ Câmara de Direito Privado, Data de Publicação: 13/08/2015).

39 "De ordinário, nos atos da vida, cada um pratica, por si, os atos que hão de influir, ativa ou passivamente na sua esfera jurídica. Os efeitos resultam de atos em que o agente é presente; pois os pratica, por ato positivo ou negativo. A regra é a presentação, em que ninguém faz o papel de outrem, isto é, em que ninguém representa" (MIRANDA, 2012, p. 307). 
Deficiência, trata de repreendê-los orientando pela adequação da legislação. Assim o fez com o Brasil, como se lê no último relatório, datado de 2015.40

Exige-se cautela quanto a essas questões, tendo em vista que não se pode regressar ao período no qual se aplicava o critério do status, qualificando o sujeito como incapaz apenas pelo fato da deficiência, e tampouco se pode aplicar o critério da funcionalidade, compreendendo-se tal capacidade de resposta como um talento a se exercer de forma insular. A funcionalidade do sujeito para responder aos desafios da vida pode ser integrada pelo meio externo e, no que se refere à capacidade civil, o sistema de apoio seria um instrumento adequadíssimo para tanto.

\section{Conclusão}

1. A CDPD implementou uma mudança paradigmática na abordagem da deficiência. Para garantir a inclusão da pessoa com deficiência, reconheceu sua personalidade jurídica, sua autonomia e sua capacidade jurídica em igualdade de condições com as demais pessoas.

2. A capacidade jurídica de que trata o art.12 da CDPD refere-se ao duplo aspecto da capacidade: de gozo e de exercício.

3. A CDPD não adota qualquer critério de abordagem da deficiência para restringir a capacidade, isto é, não adota o status approach, o outcome approach ou o functional approach.

4. Para facilitar o exercício da capacidade jurídica àqueles que necessitam de apoio intenso ou moderado, implementou um sistema de apoio e salvaguarda que consiste no necessário suporte sem a mitigação da capacidade jurídica.

5. Por meio do EPD, o Brasil instituiu a tomada de decisão apoiada, que atende aos pressupostos da CDPD.

6. Remanesce dúvida quanto à solução da curatela, que se mantém como um instrumento substitutivo de vontade e que implica restrição à capacidade jurídica da pessoa com deficiência.

7. Embora a CDPD não tenha revogado os sistemas de substituição de vontade, não permite que a deficiência seja o critério utilizado para a sua aplicação. Eventual medida restritiva da capacidade deve ser justificada na situação específica do sujeito e não no critério da deficiência.

\section{Referências}

ARAUJO, Luis Alberto David; RUZYK, Carlos Eduardo Pianovski. A perícia multidisciplinar no processo de curatela e o aparente conflito entre o Estatuto da Pessoa com Deficiência e o Código de Processo Civil: Reflexões metodológicas à luz da teoria geral do direito. R. Dir. Gar. Fund., Vitória. v. 18, n. 1, p. 227-256, jan./abr. 2017.

40 De acordo com o relatório da ONU, o EPD não está adequado aos ditames da Convenção. Supõe-se que essa possibilidade de substituição da vontade pela curatela, que acaba remetendo a pessoa à condição de relativamente incapaz, seja o ponto objeto de maior crítica. "III. Principal areas of concern and recommendations. A. General principles and obligations (arts. 1-4) [...] 6. The Committee is concerned at the lack of a coherent and comprehensive disability strategy to implement the human rights model of disability established in the Convention and harmonize the State party's legislation, policies and programmes. 7. The Committee recommends that the State party develop a disability strategy to implement the human rights model of disability. The Committee further recommends that, in consultation with organizations of persons with disabilities, the State party initiate a systematic review of existing legislation, policies and programmes and, where necessary, brings them into line with the Convention. This should include a review of any legislation, policies or programmes upon which the rights of persons with disabilities are restricted or denied on the basis of impairment, or where services or benefits to persons with disabilities lead to their segregation or exclusion. 8. The Committee is concerned that the Statute of Persons with Disabilities does not meet all of the State party's obligations under the Convention." Tradução livre: "III. Principais áreas de preocupação e recomendações. A. Princípios e obrigações gerais (arts. 1-4) [...] 6. O Comitê está preocupado com a falta de uma estratégia coerente e abrangente para implementar o modelo de direitos humanos de abordagem da deficiência estabelecido na Convenção e harmonizar a legislação do Estado-parte com as políticas e programas pertinentes. 7. O Comitê recomenda que o Estado Parte desenvolva uma estratégia de abordagem da deficiência para implementar o modelo de deficiência de direitos humanos. O Comitê recomenda ainda que, em consulta com organizações de pessoas com deficiência, o Estado-parte inicie uma revisão sistemática da legislação, políticas e programas existentes e, quando necessário, os alinhe à Convenção. Isto deve incluir uma revisão de toda legislação, políticas ou programas que possam restringir ou negar os direitos das pessoas com deficiência com base no critério da deficiência, ou onde os serviços ou benefícios para pessoas com deficiência levem à sua segregação ou exclusão. 8. O Comitê está preocupado com o fato de que o Estatuto das Pessoas com Deficiência não cumpre todas as obrigações do Estado Parte sob a Convenção". (Grifo intencional). Disponível em: <http://acnudh. org/comite-sobre-los-derechos-de-las-personas-con-discapacidad-crpd-2015/>. Acesso em: 10 mar. 2018. 
BARIFFI, Francisco. EI regimen jurídico internacional de la capacidad juridical de las personas con discapacidad. Madrid: Cinca c/ General Ibanez Íbero, 2014.

CANGUILHEM, G. O conhecimento da vida. Rio de Janeiro: Forense Universitária, 2012.

CONCIL OF EUROPE. Who gets to decide? Right to legal capacity for persons with intellectual and psychosocial disabilities. 2012. Disponível em: <https://wcd.coe.int/ViewDoc. jsp?p=\&id=1908555\&direct=true $>$. Acesso em: 11 fev. 2018.

CORDEIRO, Antônio Menezes. Tratado de Direito Civil - Parte geral. Coimbra: Almedina, 2011. v. IV.

DANDHA, Amita. Legal capacity in the disability rights in the rights convention: stranglehold of the past or lodestar for the future? Syracuse Journal of International Law \& Commerce, Nova lorque, v. 34, p. 429-462, 2007.

DÍEZ-PICAZO, Luiz. Sistema de derecho civil. Madrid: Tecnos, 2003.

FERRAJOLI, Luigi. Los fundamentos de los derechos fundamentales. Madrid: Trotta, 2001.

GAUDENZI, Paula; ORTEGA, Francisco. Problematizando o conceito de ciência a partir das noções de autonomia e normalidade. Ciencia \& saúde coletiva, Rio de Janeiro, v. 21, n. 10, p. 3061-3070, out. 2016. Disponível em: <http://www.scielo.br/scielo.php?pid=S1413-81232016001003061\&script=sci_ abstract>. Acesso em: 03 fev. 2018.

LEITE, Glauber Salomão. O regime jurídico da capacidade civil e a pessoa com deficiência. In: FERRAZ, Carolina Valença et al. (Org.). Manual dos direitos da pessoa com deficiência. São Paulo: Saraiva, 2012.

LÔBO, Paulo. Direito civil: parte geral. São Paulo: Saraiva, 2010.

MACHADO, Diego Carvalho. Autonomia privada, consentimento e corpo humano: para a construção da própria esfera privada na era tecnológica. Revista Trimestral de Direito Civil, Rio de Janeiro, n. 37, p.17-52, jan./mar. 2009.

MEIRELES, Rose Melo Venceu et al. O cuidado com o menor de idade na observância da sua vontade. In: PEREIRA, Tânia da Silva; OLIVEIRA, Guilherme. O cuidado como valor jurídico. Rio de Janeiro: Forense, 2008. p. 335-354.

MENEZES, Joyceane Bezerra de; BODIN DE MORAES, Maria Celina. Autoridade parental e privacidade do filho menor: o desafio de cuidar para emancipar. Novos Estudos Jurídicos - Eletrônica, [S.I.], v. 20, n. 2, p. 501-532, maio-ago. 2015. Disponível em: <http://siaiweb06.univali.br/seer/index.php/nej/article/ view/7881/4466>. Acesso em: 31 jul. 2018.

MENEZES, Joyceane Bezerra de; TEIXEIRA, Ana Carolina Brochado. Desvendando o conteúdo da capacidade civil a partir do Estatuto da Pessoa com Deficiência. Pensar - Revista de Ciências Jurídicas, Fortaleza, v. 21, n. 2, p. 568-599, 2016. Disponível em: <http://periodicos.unifor.br/rpen/article/ view/5619>. Acesso em: 21 mar. 2018.

MENEZES, Joyceane B. O direito protetivo no Brasil após a Convenção sobre a Proteção da Pessoa com Deficiência: impactos do novo CPC e do Estatuto da Pessoa com Deficiência. Civilística, Rio de Janeiro, a. 4, n. 1, p. 1-34, jan./jun. 2015. Disponível em: <http://civilistica.com/o-direito-protetivo-nobrasil/>. Acesso em: 21 mar. 2018.

MENEZES, Joyceane B. Tomada de decisão apoiada: instrumento de apoio ao exercício da capacidade civil da pessoa com deficiência instituído pela Lei Brasileira de Inclusão (Lei no.13.146/2015). Revista do Instituto Brasileiro de Direito Civil, v. 9, n. 3, p. 31-57, jul./set. 2016. Disponível em: <https://www. ibdcivil.org.br/image/data/revista/volume9/rbdcivil_vol_9_03_tomada-de-decisueo-apoiada.pdf>. Acesso em: 12 jan. 2018.

PALACIOS, Augustina; BARIFFI, Francisco. Capacidad Juridica, discapacidad y derechos humanos. Ediar: Buenos Aires, 2012. 
PALACIOS, Agustina; ROMAÑACH, Javier. El modelo de la diversidade: La bioética y los derechos humanos como herramientas para alcanzar la plena dignidad en la diversidad funcional. Espanha: Diversitas- AIES, [s./d.].

PECES-BARBA, Gregório. La dignidad de la persona desde la Filosofia del Derecho. Madrid: Dykinson, 2003. p. 28-55. (Col. Cuadernos Bartolomé de las casas, n. 26).

PERLINGIERI, Pietro. Perfis do direito civil. Introdução ao direito civil constitucional. Trad. Maria Cristina De Cicco. Rio de Janeiro: Renovar, 2002.

PERLINGIERI, Pietro. O direito civil na legalidade constitucional. Trad. Maria Cristina De Cicco. Rio de Janeiro: Renovar, 2008.

RODOTÀ, Stéfano. Dal soggetto alla persona. Napoli: Scientifica, 2011.

ROIG, Rafael Asís. Sobre capacidade y derechos. In: AVILÉS, Maria del Carmen B.; AGÓN, Oscar Celador; FERNANDEZ, Félix Vaca (Coord.). Perspectivas atuales de los sujetos de derecho. Madrid: Dykinson, 2012. p. 37-56.

ROIG, Rafael Asís. Derechos humanos y discapacidad - Algunas reflexiones derivadas del análisis de la discapacidad desde la teoría de los derechos. Disponível em: < https://e-archivo.uc3m.es/bitstream/ handle/10016/9401/derechos_asis_2007.pdf?sequence=1 >. Acesso em: 26 mar. 2018.

ROIG, Rafael Asís. Sobre la capacidad. Papeles el tiempo de los derechos. Disponível em: < https://earchivo.uc3m.es/bitstream/handle/10016/7828/wp32.pdf?sequence=1>. Acesso em: 12 mar. 2018.

STANZIONE, Pasquale; SCIANCALEPORE, Giovanni. Minori e diritti fondamentali. Milano: Giuffrè, 2006.

TEIXEIRA, Ana Carolina Brochado; PENALVA, Luciana Dadalto. Autoridade parental, incapacidade e melhor interesse da criança: Uma reflexão sobre o caso Ashely. Revista de Informação Legislativa, Brasília, ano 45, n. 180, p. 293-304, out./dez. 2008.

TEPEDINO, Gustavo. A tutela constitucional da criança e do adolescente: projeções civis e estatutárias. In: SIMÃO, José Fernando et al. (Org.). Direito de família no novo milênio: estudos em homenagem ao Prof. Álvaro Villaça Azevedo. São Paulo: Atlas, 2010. p. 415-436.

TEPEDINO, Gustavo; OLIVA, Milena Donato. Personalidade e capacidade na legalidade constitucional. In: MENEZES, Joyceane Bezerra de (Org.). Direito das pessoas com deficiência psíquica e intelectual nas relações privadas. Convenção sobre os direitos da pessoa com deficiência e Lei Brasileira de Inclusão. Rio de Janeiro: Progresso, 2016. p. 227-248.

TRINDADE, Bruno. Evolução nas próteses leva à melhora nas performances. 0 tempo, Minas Gerais. 01 de maio de 2016. Disponível em: <http://www.otempo.com.br/hotsites/rio-2016/ evolu\%C3\%A7\%C3\%A3o-nas-pr\%C3\%B3teses-leva-\%C3\%A0-melhora-nas-performances-1.1290035>. Acesso em: 16 abr. 2018.

\section{Autora convidada}

